Research Article

\title{
Subjective well-being and social-emotional loneliness of university students: The mediating effect of the meaning of life
}

\author{
Ahmet Çağlar Özdoğan \\ Yozgat Bozok University, Faculty of Education, Turkey
}

\begin{abstract}
This study examines the relationship between subjective well-being and social and emotional loneliness of university students through the meaning and purpose of life. The participants of the study consisted of the 477 university students, who study at the Faculty of Education. Three hundred and seven of them were females and 170 of them were males. The age of the participants ranged between 18 and 33 . The data used in the study were collected using the satisfaction with life scale, the positive and negative affect scale, the meaning and purpose of life scale, and the social and emotional loneliness scale. Data were analyzed using correlation and path analyses. The results of the correlation analyses showed that there were significant relationships between the variables of subjective well-being, social and emotional loneliness and the meaning and purpose of life. Likewise, the findings of path analyses revealed that social and emotional loneliness significantly predicted subjective well-being through the meaning and purpose of life.
\end{abstract}

Keywords: Subjective well-being; Social and emotional loneliness; The meaning and purpose of life

Article History: Submitted 12 August 2020; Revised 29 December 2020; Published online 19 January 2021

\section{Introduction}

University years, usually coinciding with the end of adolescence and the beginning of early adulthood, constitute a transition period in life which is an important phase that brings about social changes such as relationships and new habits (Wheaton, 1990). During this period, individuals become more autonomous and independent from their families, and have the opportunity to engage in close relationships with their peer groups. However, especially during university years, not all students can establish a close relationship with their peer groups, and the feeling of loneliness becomes inevitable for those who have also moved away from their families (Moeller \& Seehuus, 2019). Therefore, individuals in this period can often experience a feeling of loneliness (Schlossberg et al., 1995) or could be more sensitive to loneliness (Qualter et al., 2015).

Loneliness is a negative psychological condition that occurs based on the difference between the existing social relationship level and the social relationship level the individual would like to

Address of Corresponding Author

Ahmet Çağlar Özdoğan, Yozgat Bozok University, Faculty of Education, Department of Psychological Counseling and Guidance, 66000, Yozgat, Turkey.

$\triangle$ caglarozdogan@gmail.com

0000-0003-1406-4155

How to cite: Özdoğan, A. Ç. (2021). Subjective well-being and social-emotional loneliness of university students: The mediating effect of the meaning of life. Journal of Pedagogical Research, 5(1), 18-30. http:/ / dx.doi.org/10.33902/JPR.2021066865 
achieve (Peplau \& Perlman, 1982). Despite the existence of various classifications in the literature, mainly two types of loneliness viz. social loneliness and emotional loneliness stand out (Weiss, 1973). While social loneliness is caused by the lack of relationship with friends or by being in an environment that lacks adequate opportunities to fulfil the need for socialization, emotional loneliness is caused by the lack of emotional bonding with people, the bonding which takes place between kin (Utz et al., 2014; Weiss, 1973). Social and emotional loneliness are related to problems in different areas, and therefore can lead to different psychological and emotional issues (Salo et al., 2019). The feeling of loneliness or the fear of being alone can lead to the feelings of lack of meaning and emptiness (Geçtan, 2004).

In a study conducted by Diehl et al. (2018) on the social and emotional loneliness levels of university students, it was found that $7.7 \%$ of the participants in the sample group experienced serious emotional loneliness, and 3.2\% experienced serious social loneliness. Of all the participants, $32.4 \%$ experienced loneliness at a moderate level (ibid, 2018). In another study conducted in England, it was found that $34 \%$ of the students between the ages of 18-24 experienced loneliness to a certain degree (YouGov, 2016). Due to the increasing feeling of loneliness, mental health problems are quite common among university student populations (Musiat et al., 2018). Various studies in the literature have shown that loneliness is a serious issue determined to be highly associated with pathological conditions such as depression (Kılınç et al., 2020; Lee \& Bierman, 2019; Yavuzer et al., 2019), anxiety (Moeller \& Seehuus, 2019), and suicide (Chang et al., 2019; Chang et al., 2017).

The feeling of loneliness or the fear of being alone lead to feelings of meaninglessness and emptiness (Geçtan, 2004), since loneliness is not only about the feeling of being alone, rather the individual can also feel lonely in a social environment. This situation is mostly related to the lack of meaning in life and the sad feeling brought about by loneliness is due to the individuals not being in a social environment that will satisfy them (Weiten et al., 2015).

Human beings are social entities in essence and the existence of social relations is an important factor which increases the importance of life and positive feelings experienced. In other words, while establishing social relations give meaning to people's lives, loneliness decreases a person's sense of meaning in life (Mwilambwe-Tshilobo et al., 2019). Conceptually, meaning of life means "the meaning formed by the individual regarding her existence and the nature of her existence, and feeling important" (Li, et al., 2000, p.122). Although several researchers in the field have indicated different sources of meaning in life, most of these definitions include close relationships with others. (Emmons, 2005; Frankl, 2009; Wong, 1998). Various studies in the literature have revealed that there is a strong relationship between the sense of meaning and loneliness (Lambert et al., 2013; Stillman et al., 2009).

In the literature regarding meaning of life, there are two different structures: the existence of meaning in life and the search for meaning in life (Steger \& Fraizer, 2005; Steger, 2009). The meaning of life is subjective and can arise from many different sources (Abeyta et al., 2017). Research has also showed that the meaning of life is universally related to the subjective life experiences of individuals (Krause, 2007; Ryff \& Keyes 1995; Steger et al., 2008; Zika \& Chamberlain 1992).

Perception of a meaningful life, which individuals feel subjectively in their lives, helps to maintain close social ties and encourages social participation (Stillman \& Lambert, 2013; Steptoe \& Fancourt, 2019). In the literature, the meaning and purpose of life has been accepted as an indicator of well-being, a facilitator of coping skills, and a marker of therapeutic growth (Steger et al., 2006). Studies show that the search for meaning in life is associated with social isolation (Steger et al., 2008; Kiang \& Fuligni, 2010). Womick et al., (2020) found that individuals with a high sense of meaning had high levels of subjective well-being. According to the findings of some studies in the literature, people who have higher levels of the meaning in life have higher subjective well-being levels (Cohen \& Cairns, 2011; Doğan et al., 2012; Galang et al., 2011; Ho et al., 2008; Morgan \& Fastides, 2009; Steger \& Frazier, 2005; Şahin et al., 2012). Thus, as indicated in the literature, the 
perception of a meaningful life has a positive effect on the level of subjective well-being of individuals.

The concept of meaning in life is an important aspect of happiness and subjective well-being (Morgan \& Fastides, 2009) and is the basic unit of well-being (Frankl 1963; Steger, 2012). Therefore, a meaningful life is an important factor that provides the conditions for happiness (Lent, 2004). Examined as a construct, subjective well-being is defined as "people's emotional and cognitive evaluations of their lives" (Diener, 2000, p.34). A wide variety of phenomena including satisfaction and emotional reactions regarding people's lives within the framework that they are personally responsible for play an active role in the construct ( $\mathrm{Li}$ et al., 2020). Thus, a person's positive and negative affects and life satisfaction are very important factors in subjective well-being (Diener, 2000). While positive affect refers to an individual's positive emotional state and experiences, negative affect refers to a negative mood and experiences. Life satisfaction, on the other hand, is the cognitive evaluation of a person's satisfaction with life. In terms of subjective well-being levels, if positive affect is experienced more than negative affect, and the person's cognitive judgment about the quality of life is positive, her subjective well-being is higher (Tuzgöl-Dost, 2005a). Since subjective well-being is the cognitive evaluations of individuals regarding themselves and their lives, many psychological factors play a role in it. Among these factors, perception of a meaningful life has been found to be an important predictor of subjective well-being (Li et al., 2020). Research has showed that meaning in life is an important construct that is positively related to psychological health and well-being (García-Alandete, 2015; Kleftaras \& Psarra, 2012).

\subsection{Significance of the Study}

Research on loneliness indicates that it is experienced during all developmental phases of life (Luhmann \& Hawkley, 2016). One of the phases where it is most commonly experienced is university life (Schlossberg et al., 1995). Since psychological problems of individuals begin to arise in this phase, it is of paramount importance. (Pedrelli et al., 2015). Therefore, studies on the psychological health of university students, an important group in the society, are considered important in terms of early diagnosis, prevention studies and the effectiveness of the interventions to be applied. In this respect, it is predicted that holistic studies will help examine the construct deeply. Examining the social and emotional dimensions of loneliness would contribute to the development of prevention and intervention methods, and pave the way for the future research to be carried out in this context.

\subsection{Purpose of the Study}

Loneliness, which emerges as an unpleasant affect as a result of the insufficiency of social relations, creates an obstacle for people to live a meaningful life, and negatively affects their subjective wellbeing. Within the framework of the literature mentioned above, the purpose of this study is to investigate the direct effects of loneliness on the meaning and purpose of life, the direct effects of the meaning and purpose of life on well-being, and the indirect effects of the meaning and purpose of life in the relationship between social and emotional loneliness and subjective well-being. Concluding from the literature reviewed by the researcher, the fact that there are no holistic studies regarding the existence of such an indirect effect, and the fact that social and emotional dimensions of loneliness have not been emphasized in the literature constitute the rationale for the current study. It would contribute to the existing literature on well-being to conduct holistic studies and to investigate dimensions of loneliness in a deeper sense.

This study aims to investigate the relationships between social and emotional loneliness, the meaning and purpose of life and subjective well-being, and to find out direct and indirect predictors of these relationships. Within this scope, the research questions of the study are as follows:

i) Is there a significant relationship among social and emotional loneliness, the meaning and purpose of life, and subjective well-being?

ii) Does social and emotional loneliness predict the meaning and purpose of life significantly? 
iii) Does the meaning and purpose of life predict subjective well-being significantly?

iv) Does social and emotional loneliness predict subjective well-being through the meaning and purpose of life?

\section{Method}

\subsection{Research Design}

This study is a descriptive study in a correlational model aimed at examining the social and emotional loneliness levels and subjective well-being of university students through the meaning and purpose of life. Correlational studies are used to examine whether two or more variables affect each other or not (Fraenkel et al., 2012).

\subsection{Participants}

The participants of the study consisted of the 477 university students who study at the Faculty of Education. Three hundred and seven of them were females and 170 of them were males. The age of the participants ranged between 18 and 33. Students of a variety of departments in the Faculty of Education were included in the study with the aim of providing diversity. $13.5 \%$ of the participants were students at the department of Foreign Language Education, $16.7 \%$ of them were at Guidance and Psychological Counseling, $17.7 \%$ were at Primary Education, $18.4 \%$ were at Primary Mathematics Education, $13.9 \%$ were at Science Education, and $19.8 \%$ of them were at Preschool Education. Freshman students constituted $27.6 \%$ of the participants, $26.2 \%$ of the participants were sophomores, $23.2 \%$ were juniors, and $23 \%$ were seniors.

\subsection{Instruments}

\subsubsection{The satisfaction with life scale}

The Positive and Negative Affect Scale was developed by Watson et al. (1988) and the Turkish adaptation study was carried out by Gençöz (2000). There are 20 items in the scale to evaluate 10 positive and 10 negative affect, and the scale has a two-factor structure. In the original form of the scale, the internal consistency coefficient for positive affect was found to be .88 , and for negative affect it was .87. In the adaptation study of the scale, the two-factor structure of the scale was confirmed and the internal consistency coefficient of the positive affect sub-dimension was found to be .83 and the internal consistency coefficient of the negative affect sub-dimension was found to be .86 . The internal consistency coefficients for the current study were .82 for the positive affect and .84 for negative affect.

\subsubsection{The meaning and purpose of life scale}

The Meaning and Purpose of Life Scale was developed by Aydin et al. (2015) on a Turkish sample to evaluate the meaning and purpose of life. The scale has a two-factor structure which are the meaning and purpose of life and the lack of meaning and purpose in life. Having a total of 17 items, the scale has a 5-point Likert type rating. Internal consistency coefficient of the scale was found to be .91 , the split-half reliability coefficient was .81 , and the test-retest reliability coefficient was .74. The internal consistency coefficient for the current study was found to be 87 .

\subsubsection{The social and emotional loneliness scale}

The Social and Emotional Loneliness Scale developed by DiTommaso et al. (2004) was adapted into Turkish by Çeçen (2007). The first form of the scale consisted of 37 items in total, but a short form consisting of 15 items was developed later. The scale has a 7-point Likert-type rating. It consists of three dimensions which are romantic loneliness, family loneliness, and social loneliness.

Family and romantic loneliness dimensions comprise the emotional loneliness dimension of the scale while the social loneliness sub-dimension constitutes social loneliness. In the adaptation study of the scale, the internal consistency coefficient for the romantic loneliness sub-dimension 
was found to be .83 , and .77 was found for the family sub-dimension, and .74 was found for social loneliness. As for the current study, the coefficients were found as $.80, .78 .77$ respectively.

\subsection{Procedure}

The data for the study were collected, using the data collection instruments, from the participants who were students at the Faculty of Education during the 2019-2020 academic year. In the first stage, the data were collected from 492 participants in total. First, extreme values in the data were examined. Values below and above the $z$ score $\pm 3.3(\mathrm{p}<.001)$ range are considered to be extreme values (Tabachnick \& Fidel, 2013). According to the results of the $z$ score analysis, 11 cases were excluded from the data set. Then, the multivariate extreme value analysis was conducted using and Mahalonobis distance values. Four more cases determined accordingly were excluded from the analysis. To evaluate multicollinearity, tolerance values, condition index $(\mathrm{CI})$ and the variance inflation rates (VIF) were examined. According to Hair et al. (1998), the VIF value should be less than 10 and the tolerance values should be above 10, or the CI value should be below 30 in order to avoid multicollinearity. Based on the results of the analyses, it was observed that all the values were within the specified ranges ( $\mathrm{CI}=$ from 1.073 to $2.928 ; \mathrm{VIF}=$ from.342 to .932$)$.

\subsection{Data Analysis}

The descriptive statistics were calculated first, and then Pearson correlation analysis was performed to determine the relationships among the variables. Path analysis was utilized to determine the predictive effect of social and emotional loneliness on the levels of subjective wellbeing through the meaning and purpose of life. IBM SPSS Statistics 23.00 and Mplus 7.0 were used for the aforementioned analyses.

\section{Results}

\subsection{Descriptive Statistics and Correlations}

The descriptive statistics, skewness, and kurtosis values are shown in Table 1 . As can be seen in Table 1, the assumption of normality is not violated for the variables of the study (Skewness: form -0.01 to 0.86 ; Kurtosis: from -1.04 to 0.22 )

Table 1

Descriptive Statistics of Variables

\begin{tabular}{lcccccc}
\hline Variables & $\overline{\boldsymbol{X}}$ & SD & Skewness & SE & Kurtosis & SE \\
\hline 1. SWB & 36.57 & 12.2 & -0.35 & 0.11 & 0.28 & 0.22 \\
2. Life.Sat & 23.82 & 5.65 & -0.62 & 0.11 & 0.24 & 0.22 \\
3. Pos.Aff & 34.4 & 5.63 & -0.01 & 0.11 & -0.43 & 0.22 \\
4. Neg.Aff & 22.47 & 6.24 & 0.44 & 0.11 & -0.32 & 0.22 \\
5. Fam.Lon & 13.61 & 7.7 & 0.86 & 0.11 & -0.22 & 0.22 \\
6. Rom.Lon & 17.79 & 8.59 & 0.15 & 0.11 & -1.04 & 0.22 \\
7. Soc.Lon. & 14.1 & 7.48 & 0.65 & 0.11 & -0.73 & 0.22 \\
8. MoL & 44.28 & 5.72 & -0.24 & 0.11 & -0.4 & 0.22 \\
9. MlessoL & 14.88 & 6.1 & 0.44 & 0.11 & -0.95 & 0.22 \\
\hline
\end{tabular}

SWB: Subjective Well-Being, Life.Sat: Life Satisfaction, Pos.Feel: Positive Feeling, Neg.Aff: Negative Affect, Fam.Lon: Family Loneliness, Rom.Lon: Romantic Loneliness, Soc.Lon: Social Loneliness, MoL.: Meaning and Purpose of Life, MlessoL: Meaninglessness of Life and Lack of Purpose

In order to determine the relationships among variables in the research, Pearson correlation analysis was carried out, and the results are shown in Table 2. As shown in Table 2, there are significant correlations in the negative direction between subjective well-being and romantic loneliness $(r=-.36, p<.01)$, between subjective well-being and family loneliness $(r=-.40, p<.01)$ and between subjective well-being and social loneliness $(r=-.35, p<.01)$. In addition, there are significant negative correlations between the meaning and purpose of life and family loneliness 
$(r=-.54, p<.01)$, between the meaning and purpose of life and romantic loneliness $(r=-.52, p<.01)$, and between the meaning and purpose of life and social loneliness $(r=-.54, p<.01)$. Moreover, there are significant positive correlations between the meaning and purpose of life and subjective wellbeing $(r=.43, p<.01)$, and between the meaning and purpose of life and the meaninglessness and purposelessness of life $(r=-.39, p<.01)$.

Table 2

Correlations among Subjective Well-Being, Social and Emotional Loneliness and Meaning and Purpose of Life Scales

\begin{tabular}{lcllllllll} 
Variables & $\mathbf{1}$ & $\mathbf{2}$ & $\mathbf{3}$ & $\mathbf{4}$ & $\mathbf{5}$ & $\mathbf{6}$ & $\mathbf{7}$ & $\mathbf{8}$ & $\mathbf{9}$ \\
\hline 1. SWB & - & & & & & & & & \\
2. Life.Sat & $.72^{* *}$ & - & & & & & & \\
3. Pos.Feel & $.61^{* *}$ & $.26^{* *}$ & - & & & & & \\
4. Neg.Feel & $-.58^{* *}$ & $-.27^{* *}$ & -0.3 & - & & & & \\
5. Fam.Lon & $-.40^{* *}$ & $-.38^{* *}$ & $-.12^{* *}$ & $.23^{* *}$ & - & & & \\
6. Rom.Lan & $-.36^{* *}$ & $-.25^{* *}$ & $-.27^{* *}$ & $.09^{*}$ & $.59^{* *}$ & - & & \\
7. Soc. Lon. & $-.35^{* *}$ & $-.28^{* *}$ & $-.13^{* *}$ & $.21^{* *}$ & $.66^{* *}$ & $.58^{* *}$ & - & \\
8. MOL & $.43^{* *}$ & $.33^{* *}$ & $.35^{* *}$ & $-0,08$ & $-.54^{* *}$ & $-.52^{* *}$ & $-.54^{* *}$ & - & \\
9. MlessOL & $-.39^{* *}$ & $-.28^{* *}$ & $-.18^{* *}$ & $.19^{* *}$ & $.59^{* *}$ & $.59^{* *}$ & $.61^{* *}$ & $-.55^{* *}$ & - \\
\hline
\end{tabular}

\subsection{Findings of Path Analysis Testing the Hypothetical Model}

In order to examine whether subjective well-being and social and emotional loneliness levels of university students were predicted through the meaning of life, path analysis was performed with Mplus 7.0, and the model shown in Figure 1 was tested. All variables in the model were defined as observed variables and the path analysis was performed on these observed variables. According to Kline (2011), at least four values including chi-square test, RMSEA, CFI and SRMR, should be reported for goodness of fit assessment in the model. The fit indices in this model were as follows: $((\mathrm{X} 2(19)=108.474, \mathrm{p}<.05 ; \mathrm{CFI}=.96 ; \mathrm{TLI}=.93 ; \mathrm{RMSEA}=.08 ; \mathrm{SRMR}=.04)$ and according to the findings obtained from the analysis, it was determined that the obtained model had an acceptable fit (Kline, 2011; Tabachnick \& Fidell, 2013).

Table 3

Main Fit Indices and Reference Ranges (Brown, 2015; Kline, 2011; Schreiber, 2006; Tabachnick \& Fidell, 2013)

\begin{tabular}{lcc}
\hline Fit Index & Good Fit & Acceptable Fit \\
\hline X 2 /df (Chi-square / degree of freedom) & $\leq 3$ & $\leq 5$ \\
CFI & $\geq 0,97$ & $\geq 0,95$ \\
TLI & $\geq 0,95$ & $\geq 0,90$ \\
SRMR & $\leq 0,05$ & $\leq 0,10$ \\
RMSEA & $\leq 0,05$ & $\leq 0,08$ \\
\hline
\end{tabular}

When the parameter estimates obtained from the model were examined (see Figure 1), it was concluded that the meaning of life was predicted by family loneliness $(\beta=-.17)$, by romantic loneliness $(\beta=-.16)$, and by social loneliness $(\beta=-.19)$. These variables explain $28 \%$ of the variance in meaning of life. Findings also indicated that the meaninglessness of life was predicted by family loneliness

$(\beta=.22)$, by romantic loneliness $(\beta=.23)$, and by social loneliness $(\beta=.28)$. These variables explain $19 \%$ of the variance in the meaninglessness of life. Moreover, it was found that the meaning of life predicted subjective well-being $(\beta=.68)$ explaining the $32 \%$ of the variance in it, and the meaninglessness of life predicted subjective well-being $(\beta=-.49)$ explaining $25 \%$ of the variance. 
Figure 1

Path model with standardized path coefficients

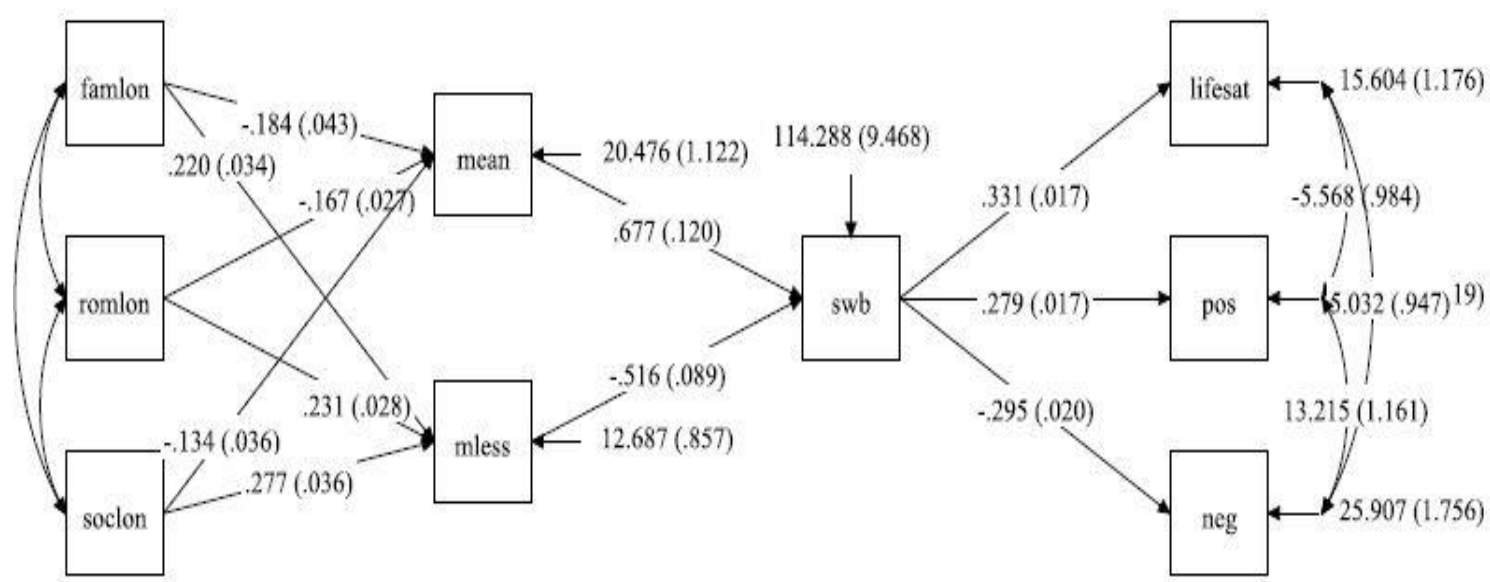

Famlon: Family Loneliness, Romlon: Romantic Loneliness, Soclon: Social Loneliness Mean: Meaning and Purpose of Life Mless: The Meaninglessness of Life and Lack of Purpose Swb: Subjective Well Being Lifesat: Life Satisfaction, Pos: Positive Affect, Neg: Negative Affect

\subsection{Findings regarding the Indirect Effects}

In the model structured, it was found out that family loneliness significantly predicted subjective well-being through the meaning of life (Path Coefficient $=-.12$ ) and the meaninglessness of life (Path Coefficient $=-.11)(p<.05)$. Romantic loneliness predicted subjective well-being significantly $(p<.05)$ through the meaning of life (Path Coefficient $=-.11)$ and the meaninglessness of life (Path Coefficient $=-.11)$. Also, social loneliness predicted subjective well-being significantly $(p<.05)$ through the meaning of life (Path Coefficient $=-.13$ ) and the meaninglessness of life (Path Coefficient $=-.14)$. The model explained $24 \%$ of the variance in subjective well-being.

Consequently, the increase in social and emotional loneliness positively predicted the meaninglessness of life, and negatively predicted the meaning of life. In addition, subjective wellbeing is predicted by meaninglessness of life negatively and is predicted by the meaning of life positively. Due to the predictive effects of all values within the model and the goodness of fit of the model, the predictive power of the model could be evaluated as not being coincidental. The effect of social and emotional loneliness on the meaninglessness of life and the effect of the meaning of life on subjective well-being were found to be higher. This clearly indicated the predictive power of positive features on positive features and the predictive power of negative features on negative features in the model.

\section{Discussion}

Within the scope of the model that was formed in the study, it was found that social and emotional loneliness significantly predicted subjective well-being through the meaning and purpose of life. The results obtained showed that the hypothetical model examined within the study was valid.

\subsection{Discussion on the Direct Effects in the Model}

The findings regarding the direct effects in the model revealed that social and emotional loneliness significantly predicted the meaning and meaninglessness of life, and the meaning and meaninglessness of life significantly predicted subjective well-being.

When the findings obtained from the research study are examined, it can be seen that all subdimensions of social and emotional loneliness (family, romantic and social) significantly predicted the meaning and meaninglessness of life. Looking at the relevant literature, it is revealed that the number of the studies on sub-dimensions of loneliness is quite limited. When the results obtained from the study are examined in relation to the literature on loneliness, it can be concluded that they are in parallel with previous research results (Altıparmak, 2019; Doğan et al., 2012; 
Mwilambwe-Tshilobo et al., 2019; Stillman et al., 2009; Stillman \& Lambert, 2013; Steptoe \& Fancourt, 2019; Lambert et al., 2013; Tomsik, 2015). Conceptually, rather than a simple dictionary definition, the meaning of life is a way of making sense of people's existence and this subjective assessment of the meaning of life is related to how meaning is traditionally evaluated. The common point for many researchers in their evaluations regarding the sources of meaning in life has been the social relations (Frankl, 2009; Emmons, 2005; Wong, 1998). Building and maintaining positive close relationships can be characterized as one of the basic motivations for people (Buss, 1990; Maslow, 1968). Therefore, the basic aspect of all efforts of people is to establish close relationships with others, and finding the meaning in life is acquired socially. Becoming alone by losing contact with others decreases people's perception of a meaningful life and increases the threat of meaninglessness (Stilmann et al., 2009). In a study conducted by Yeung and Fan (2013), it was found that with the increase of social isolation and subjective loneliness, a significant decrease in the perception of a meaningful life occurs. In addition, it has been showed that social support perceived by family, friends and significant others has a positive significant relationship with the perception of a meaningful life (Alice et al., 2019; Boullion et al., 2020; Lin et al., 2020). Furthermore, it was found in some studies that individuals who are engaged in romantic relationships have higher levels of meaning in life (Klefteras \& Pserra, 2012; Taş, 2011). Thus, it can be discussed that the effects of the level of socialization which increases people's perception of a meaningful life, and the effects of social and emotional loneliness which constitutes the insufficiency of socialization level on the perception of a meaningful life are expected results. It is obvious that the results obtained from the current study support the relevant literature and structure.

Another finding of the study was that the meaning and meaninglessness of life predicted subjective well-being significantly. In a meta-analysis study conducted on the construct (Li et al., 2020), it was found that there are significant relationships between subjective well-being and the meaning of life and the search for meaning in life with effect sizes close to medium. These findings have indicated that individuals who have an open and stable meaning of life have higher levels of subjective well-being. Similar results have been obtained by several research studies in literature (Da Luz Vale Dias \& Sant'Anna Dos Santos Vera, 2020; Krock \& Gerymski, 2019; Womick et al., 2020). These studies have revealed the significant relationship between the perception of a meaningful life and happiness. Factors such as a feeling that life is important and having a certain sense of purpose in life were found to have a direct effect on people's well-being (Steger et al., 2011). In conclusion, the results obtained from the current study are in consistence with the related literature.

\subsection{Discussion on the Indirect Effects in the Model}

Regarding the indirect effects in the model, it was found that social and emotional loneliness predicted subjective well-being through the meaning and purpose of life. To put it more clearly, family, social and romantic loneliness have a negative effect on meaning and purpose of life, and the decrease in meaning in life has a negative effect on subjective well-being levels.

Regarding the model structured in the current study, no research finding has been encountered in the relevant literature; however, the findings can be compared and contrasted at some points. In a study where the variables in this study were directly addressed together, it was found that the meaning of life was a significant positive predictor of subjective well-being, and it also had a significant negative relationship with loneliness (Itzick et al., 2016). It could be observed that the direct structure among the variables significantly predict each other in individuals within the same sample group. In addition, the effect of social factors on people's having a meaningful life (Heng et al., 2020) and the effect of having a meaningful life on subjective well-being (You \& Lim, 2018) indicate that social and emotional loneliness would predict subjective well-being through the meaning and purpose of life. Domagala-Krecioch and Majerek (2013) stated that individuals who feel the social and psychological effects of loneliness generally have lower levels of satisfaction 
with their lives and this causes a decrease in their well-being levels. In a study examining the emotional dimension of loneliness by comparing the groups with and without romantic relationships, it was found that individuals who were engaged in romantic relationships had significantly higher levels of life satisfaction and well-being and lower levels of loneliness (Adamczyk, 2016). The fact that meaning in life is acquired socially (Stilmann et al., 2009) and its effect on subjective well-being (Diener, 2000), which is the cognitive and emotional evaluation of life, are expected results. The findings of the current study confirmed the model formed regarding the significance of the indirect effect.

To conclude, within the framework of the model examined in the study, it was found that social and emotional loneliness significantly predicted subjective well-being through the meaning and purpose of life. The results indicated that the hypothetical model examined within the scope of the study has been valid.

\subsection{Limitations}

As in all academic works, this study has some limitations, too. Primarily, the sample group consists of the students studying at various departments of Faculty of Education of a state university. Therefore, in terms of the generalizability of the research, it may be appropriate to conduct similar studies with students of different faculties and universities based on the maximum sampling method. In addition, it would be functional to duplicate the study with students from different regions to scrutinize the socio-cultural levels of the students in the sample group, and the effect of regional conditions. In this study, having an even distribution of students at different grade levels was considered. The study can be replicated with only freshmen due to the higher effect of loneliness on them. Finally, this study was conducted in correlational research design which is one of the quantitative research methods. Besides its functionality, the study has some limitations in terms of drawing a cause-effect relationship since it is a correlations study. Therefore, studies to be done utilizing experimental design would be functional.

\subsection{Future Implications}

Considering the results of the research, some suggestions were made for both researchers and practitioners. First of all, the number of studies conducted on social and emotional loneliness and the meaning and purpose of life is limited. While there are more studies conducted on loneliness overall, they are limited to specific dimensions of loneliness; namely family, friends and romantic dimensions. It is necessary to conduct more studies on different dimensions of loneliness in order to examine the construct in more detail. In addition, the importance of dimensions of loneliness may differ according to the developmental phases that individuals are in. Thus, studies on social and emotional loneliness with different sample groups are likely to produce more determinative results. While questioning the meaning in life mostly begins in adolescence (Fry, 1998), the semantic settlement of a more stable perception of life may occur towards the end of adolescence and the beginning of young adulthood (Tomšık, 2015). In this study, individuals in university years were taken into consideration, but the construct could be studied on a different sample group and also the results obtained from this study can be compared with the results of similar studies on university groups. Although the concept of the meaning of life is seen as an integral part of human nature, this concept can have different meanings for various cultures and the people who constitute the culture. When the relevant literature is examined, some cultural differences regarding the way meaning in life is obtained and the source of meaning in life are striking (Emmons, 1999; Frankl, 2009; Reker \& Wong, 1988; Yalom, 2011). In this study, the meaning and purpose of life scale, which was developed on a Turkish sample and thought to reflect its cultural structure, was used. Therefore, the variables in the study can be reconsidered with measurement tools that reflect their own cultural elements in different cultures since this scale was developed on a Turkish sample. In this study, subjective well-being was tested through social and emotional loneliness and the meaning and purpose of life. The findings can be supported by direct and indirect studies with variables that are known to have an effect on subjective well-being. 
In terms of practitioners, the results revealed the existence of the effect of social and emotional loneliness on the meaning of life, and indirectly on subjective well-being. Therefore, practices aimed at preventing the loneliness factor, which is effective on a meaningful life and subjective well-being, would be useful. Various measurement tools (such as sociometry) and studies on students who experience loneliness, which is possible to determine through observations and interviews, will be functional, especially in school environments before university years. Studies aiming to increase students' social skills in order to reduce loneliness can be functional. In addition, some family-oriented interventions on lonely individuals can be considered within the scope of prevention activities.

\section{References}

Abeyta, A.A., Routledge, C., \& Sedikides, C. (2016). Material meaning: Narcissists gain existential benefits from extrinsic goals. Social Psychology and Personality Science, 8(2), 219-228. 7

Adamczyk, K. (2016). An investigation of loneliness and perceived social support among single and partnered young adults. Current Psychology: A Journal For Diverse Perspectives On Diverse Psychological Issues, 35(4), 674-689. https :/ / doi.org/10.1007/s1214 4-015-9337-7

Aliche, J.C., Ifeagwazi, C.M., Onyishi, I.E., \& Mefoh, P.C. (2019). Presence of meaning in life mediates the relations between social support, posttraumatic growth, and resilience in young adult survivors of a terror attack. Journal of Loss and Trauma, 24(8), 736-749. https :// doi.org/10.1080/15325024.2019.1624416

Altıparmak, D. (2019). Mediating effect of self-compassion in relationship of life purpose, life meaning and well-being of teachers (Unpublished master's thesis). İstanbul Sabahattin Zaim University.

Aydın, C., Kaya, M., \& Peker, M. (2015). Meaning and purpose of life scale: The study of its validity and reliability. Ondokuz Mayıs University, Review of the Faculty of Divinit, 38, 39-55.

Boullion, G. Q., Pavlacic, J. M., Schulenberg, S. E., Buchanan, E. M., \& Steger, M. F. (2020). Meaning, social support, and resilience as predictors of posttraumatic growth: A study of the Louisiana flooding of August 2016. American Journal of Orthopsychiatry, 90(5), 578-585. https://doi.org/10.1037/ort0000464

Buss, D.M. (1990). The evolution of anxiety and social exclusion. Journal of Social and Clinical Psychology, 9(2), 196-201. https://doi.org/10.1521/jscp.1990.9.2.196

Brown, T. A. (2015). Methodology in the social sciences. Confirmatory factor analysis for applied research (2nd ed.). The Guilford Press.

Chang, E. C., Chang, O. D., Martos, T., Sallay, V., Lee, J., Stam, K. R., ... \& Yu, T. (2017). Family support as a moderator of the relationship between loneliness and suicide risk in college students: having a supportive family matters!. The Family Journal, 25(3), 257-263. https://doi.org/10.1177/1066480717711102

Chang, E. C., Chang, O. D., Lucas, A. G., Li, M., Beavan, C. B., Eisner, R. S., McManamon, B. M., Rodriguez, N. S., Katamanin, O. M., Bourke, E. C., de la Fuente, A., Cardeñoso, O., Wu, K., Yu, E. A., Jeglic, E. L., \& Hirsch, J. K. (2019). Depression, loneliness, and suicide risk among Latino college students: A test of a psychosocial interaction model. Social Work, 64(1), 51-60. https://doi.org/10.1093/sw/swy052

Cohen, K., \& Cairns, D. (2011). Is searching for meaning in life associated with reduced subjective wellbeing? Confirmation and possible moderators. Journal of Happiness Studies, 13(2), 313-331. https:/ / doi.org/10.1007/s10902-011-9265-7

Çeçen, A.R. (2007). The Turkish short version of the social and emotional loneliness scale for adults (SELSAS): Initial development and validation, Social Behavior and Personality, 35 (6), 717-734. https://doi.org/10.2224/sbp.2007.35.6.717

Da Luz Vale Dias, M., \& Sant'Anna Dos Santos Vera, J. (2020). Meaning in life, subjective well-being and spiritual well-being in Portuguese and Brazilian young people. International Journal of Developmental and Educational Psychology. Revista INFAD de Psicología. https:// doi.org/10.17060/ijodaep.2020.n1.v2.1847

Diehl K., Jansen C., Ishchanova K., \& Hilger-Kolb J. (2018). Loneliness at Universities: Determinants of emotional and social loneliness among students. International Journal of Environment Research and Public Health, 15(9) 1865. https:/ / doi.org/10.3390/ijerph15091865

Diener, E. (2000). Subjective well-being: The science of happiness and a proposal for a national index. American Psychologist, 55, 34-43. https:// doi.org/10.1037/0003-066X.55.1.34

DiTommaso, E., Brannen, C., \& Best, L. A. (2004). Measurement and validity characteristics of the short version of the social an emotional loneliness scale for adults. Educational and Psychological Measurement, 64(1), 99-119. https:// doi.org/10.1177\%2F0013164403258450 
Domagała-Krecioch, A., \& Majerek, B. (2014). The issue of loneliness in the period of emerging adulthood. European Scientific Journal, ESJ, 9 (10). https://doi.org/10.19044/esj.2013.v9n10p\%25p

Doğan, T., Sapmaz, F., Tel, F. D., Sapmaz, S., \& Temizel, S. (2012). Meaning in life and subjective well-being among Turkish university students. Procedia-Social and Behavioral Sciences, 55, 612-617. https://doi.org/10.1016/j.sbspro.2012.09.543

Emmons, R. A. (1999). The psychology of ultimate concerns: Motivation and spirituality in personality. Guilford Press.

Emmons, R. A. (2005). Striving for The Sacred: Personal goals, life meaning and religion. Journal of Social Issues, 61(4), 731-745. https:// doi.org/10.1111/j.1540-4560.2005.00429.x

Fraenkel, J.R., Wallen, N.E., \& Hyun, H.H. (2012). How to design and evaluate research in education (Eight Edition). McGraw-Hill.

Frankl, V.E. (1963). Man's search for meaning: an introduction to logotherapy. Washington Square Press.

Fry, P. S. (1998). The development of personal meaning and wisdom in adolescence: A reexamination of moderating and consolidating factors and influences. In P. T. P. Wong \& P. S. Fry (Eds.), The human quest for meaning: A handbook of psychological research and clinical applications (p. 91-110). Lawrence Erlbaum Associates Publishers.

Galang, M. J. A., Magno, C., Paterno, V. C., \& Roldan, A. E. (2011). Meaning in life, flow and subjective wellbeing: A perspective on Filipino high school students. Phillipine Journal of Counselling Psychology, 13(1), 29-45.

García-Alandete, J. (2015). Does meaning in life predict psychological well being? The European Journal of Counselling Psychology, 3(2), 89-98.

Geçtan, E. (2004). Varoluş ve psikiyatri [Existence and psychiatry]. İstanbul: Remzi Kitabevi.

Gençöz, T. (2000). Positive and negative affect scale: Validity and reliability study. Turkish Journal of Psychology, 15(46), 19-26.

Hair, J. F., Anderson R. E., Tahtam, R. L., \& Black, W. C. (1998). Multivariate data analysis. Pearson Education.

Heng, M. A., Fulmer, G. W., Blau, I., \& Pereira, A. (2020). Youth purpose, meaning in life, social support and life satisfaction among adolescents in Singapore and Israel. Journal of Educational Change, 21(2), 299-322. https://doi.org/10.1007/s10833-020-09381-4

Ho, M. Y., Cheung, F. M., \& Cheung, S. F. (2008). Personality and life events as predictors of adolescents' life satisfaction: Do life events mediate the link between personality and life satisfaction? Social Indicators Research, 89(3), 457-471. https://doi.org/10.1007/s11205-008-9243-6

Itzick, M., Kagan, M., \& Ben-Ezra, M. (2018). Social worker characteristics associated with perceived meaning in life. Journal of Social Work, 18(3), 326-347. https:// doi.org/10.1177\%2F1468017316654345

Kılınç, G., Aylaz, R., Güneş, G., \& Harmanc1, P. (2020). The relationship between depression and loneliness levels of the students at the faculty of health sciences and the factors affecting them. Perspectives in Psychiatric Care, 56(2), 431-438. https://doi.org/10.1111/ppc.12452

Kiang, L., \& Fuligni, A. J. (2010). Meaning in life as a mediator of ethnic identity and adjustment among adolescents from Latin, Asian, and European American backgrounds. Journal of Youth and Adolescence, 39(11), 1253-1264. https:// doi.org/10.1007/s10964-009-9475-z

Kleftaras, G., \& Psarra, E. (2012). Meaning in life, psychological well being and depressive symptomatology: A Comparative Study Psychology, 3(4), 337-345. http://dx.doi.org/10.4236/psych.2012.34048

Kline, R. B. (2011). Methodology in the social sciences. Principles and practice of structural equation modeling (3rd ed.). Guilford Press.

Krause, N. (2007). Longitudinal study of social support and meaning in life. Psychology and Aging, 22(3), 456469. https:// doi.org/10.1037/0882-7974.22.3.456

Krok, D., \& Gerymski, R. (2019). Self-efficacy as a mediator of the relationship between meaning in life and subjective well-being in cardiac patients, Current Issues in Personality Psychology, 7(3), 242-251. https://doi.org/10.5114/cipp.2019.89168

Lambert, N. M., Stillman, T. F., Hicks, J. A., Kamble, S., Baumeister, R. F., \& Fincham, F. D. (2013). To belong is to matter: Sense of belonging enhances meaning in life. Personality and Social Psychology Bulletin, 39(11), 1418-1427. https:// doi.org/10.1177/0146167213499186

Lee, Y., \& Bierman, A. (2019). Loneliness as a mediator of perceived discrimination and depression: Examining education contingencies. The International Journal of Aging and Human Development, 89(2), 206227. https://doi.org/10.1177/0091415018763402 
Lent, R. W. (2004). Toward a unifying theoretical and practical perspective on well-being and psychosocial adjustment. Journal of Counseling Psychology, 51, 482-509. https://psycnet.apa.org/doi/10.1037/00220167.51.4.482

Li, J.-B., Dou, K., \& Liang, Y. (2020). The relationship between presence of meaning, search for meaning, and subjective well-being: A three-level meta-analysis based on the meaning in life questionnaire. Journal of Happiness Studies, 1-23. https:/ /10.1007/s10902-020-00230-y

Lin, Y., Xiao, H., Lan, X., Wen, S., \& Bao, S. (2020). Living arrangements and life satisfaction: Mediation by social support and meaning in life. BMC Geriatrics, 20, 136. https://10.1186/s12877-020-01541-8

Luhmann, M., \& Hawkley, L. C. (2016). Age differences in loneliness from late adolescence to oldest old age. Developmental Psychology, 52(6), 943-959. https://10.1037/dev0000117

Maslow, A. H. (1968). Toward a Psychology of Being. New York: D. Van Nostrand Company.

Moeller, R.W., \& Seehuus, M. (2019). Loneliness as a mediator for college students' social skills and experiences of depression and anxiety. Journal of Adolescence. https://10.1016/j.adolescence.2019.03.006

Morgan, J., \& Fastides, T. (2009). Measuring meaning in life. Journal of Happiness Studies, 10(2), 197-214.

Musiat, P., Potterton, R., Gordon, G., Spencer, L., Zeiler, M., Waldherr, K., et al. (2018). Web-based indicated prevention of common mental disorders in university students in four European countries - study protocol for a randomised controlled trial. Internet Interventions, 16, 35-42. https://doi.org/10.1016/j. invent.2018.02.004

Mwilambwe-Tshilobo, L., Ge, T., Chong, M., Ferguson, M.A., Misic, B., Burrow, A.L., Leahy, R.M., \& Spreng, R.N. (2019). Loneliness and meaning in life are reflected in the intrinsic network architecture of the brain. Social Cognitive and Affective Neuroscience, 14(4), 423-433. https:// doi.org/10.1093/scan/nsz021

Qualter, P., Vanhalst, J., Harris, R., Van Roekel, E., Lodder, G., Bangee, M., et al. (2015). Loneliness across the life span. Perspectives on Psychological Science, 10(2), 250-264. https://doi.org/10.1177/1745691615568999

Pedrelli, P., Nyer, M., Yeung, A., Zulauf, C., \& Wilens, T. (2015). College students: Mental health problems and treatment considerations. Academic psychiatry: The journal of the American Association of Directors of Psychiatric Residency Training and the Association for Academic Psychiatry, 39(5), 503-511. https://doi.org/10.1007/s40596-014-0205-9

Peplau, L. A., \& Perlman, D. (1982). Perspective on loneliness. In L. A. Peplau \& D. Perlman(Eds.), Loneliness: A sourcebook of current theory, research and therapy (pp. 1-18). John Wiley and Sons.

Ryff, C. D., \& Keyes, C. L. M. (1995). The structure of psychological well-being revisited. Journal of Personality and Social Psychology, 69, 719-727

Reker, G. T., \& Wong, P. T. P. (1988). Aging as an individual process: Toward a theory of personal meaning. In J. E. Birren \& V. L. Bengtson (Eds.), Emergent theories of aging (pp. 214-246). Springer.

Salo, A. E., Junttila, N., \& Vauras, M. (2020). Social and emotional loneliness: Longitudinal stability, interdependence, and intergenerational transmission among boys and girls. Family Relations, 69(1), 151165. https://doi.org/10.1111/fare.12398

Schlossberg, N. K., Waters, E. B., \& Goodman, J. (1995). Counseling Adults in Transition Linking Practice with Theory; Springer.

Schreiber, J. B., Nora, A., Stage, F. K., Barlow, E. A., \& King, J. (2006). Reporting Structural Equation Modeling and Confirmatory Factor Analysis Results: A Review. Journal of Educational Research, 99, 323-338. https://doi.org/10.3200/JOER.99.6.323-338

Steger, M. F. (2009). Meaning in life. In S. J. Lopez \& C. R. Snyder (Eds.), Oxford library of psychology. Oxford handbook of positive psychology (pp. 679-687). Oxford University Press.

Steger, M. F., Oishi, S., \& Kesebir, S. (2011). Is a life without meaning satisfying? The moderating role of the search for meaning in satisfaction with life judgments. The Journal of Positive Psychology, 6(3), 173180. https://doi.org/10.1080/17439760.2011.569171

Steger, M. F. (2012). An illustration of issues in factor extraction and identification of dimensionality in psychological assessment data. Journal of Personality Assessment, 86(3), 263-272. https://doi.org/10.1207/s15327752jpa8603_03

Steger, M. F., \& Frazier, P. (2005). Meaning in life: One link in the chain from religiousness to wellbeing. Journal of Counseling Psychology, 52(4), 574-582. https:// doi.org/10.1037/0022-0167.52.4.574

Steger, M. F., Frazier, P., Oishi, S., \& Kaler, M. (2006). The meaning in life questionnaire: Assessing the presence of and search for meaning in life. Journal of Counseling Psychology, 53(1), 80-93. https:// psycnet.apa.org/doi/10.1037/0022-0167.53.1.80 
Steger, M. F., Kashdan, T. B., Sullivan, B. A., \& Lorentz, D. (2008). Understanding the search for meaning in life: Personality, cognitive style, and the dynamic between seeking and experiencing meaning. Journal of Personality, 76, 199-228. https://doi.org/10.1111/j.1467-6494.2007.00484.x

Steptoe, A., \& Fancourt, D. (2019). Leading a meaningful life at older ages and its relationship with social engagement, prosperity, health, biology, and time use. Proceedings of the National Academy of Sciences, 116(4), 1207-1212. https:/ / doi.org/10.1073/pnas.1814723116

Stillman, T. F., Baumeister, R. F., Lambert, N.M., Crescioni, A. W., DeWall, C. N., \& Fincham, F. D. (2009). Alone and without purpose: Life loses meaning following social exclusion, Journal of Experimental Social Psychology, 45(4), 686-694. https:// doi.org/10.1016/j.jesp.2009.03.007

Stillman T. F., \& Lambert, N. M. (2013) The bidirectional relationship of meaning and belonging. In Hicks J., Routledge C. (Eds) The experience of meaning in life (pp. 305-315). Springer. https://doi.org/10.1007/97894-007-6527-6_23

Şahin, M., Aydın, B., Sarı, S. V., Kaya, S., \& Pala, H. (2012). The role of hope and meaning in life in explaining subjective well-being. Kastamonu Education Journal, 20(3), 827-836.

Tabachnick, B. G., \& Fidell, L. S. (2013). Using multivariate statistics. Pearson, Boston.

Taş, İ. (2011). The search of meaning of life, life satisfaction, social comparison and internal-external locus control in terms of different variants. (Unpublished master's thesis). Sakarya University.

Tomsik, R. (2015). Relationship of loneliness and meaning of life among adolescents. Current Trends in Educational Science and Practice, 8, 1-10.

Tuzgöl-Dost, M. (2005). Developing a subjective well-being scale: Validity and reliability studies. The Turkish Psychological Counseling and Guidance Journal, 3(23), 103-110.

Utz, R.L., Swenson, K.L., Caserta, M., Lund, D., \& deVries, B. (2014). Feeling lonely versus being alone: loneliness and social support among recently bereaved persons. The Journals of Gerontology Psychological Sciences and Social Sciences. 69(1), 85-94. https://10.1093/geronb/gbt075

Watson, D., Clark, L. A., \& Tellegen, A. (1988). Development and validation of brief measures of positive and negative affect: The PANAS Scales. Journal of Personality and Social Psychology, 47, 1063-1070.

Weiss, R. S. (1973). Loneliness: The experience of emotional and social isolation. Cambridge, MA: MIT Press.

Weiten, W., Dunn, D. S., \& Hammer, E. Y. (2015). Psychology applied to modern life: Adjustment in the 21st century. Cengage: Wadsworth.

Wheaton, B. (1990). Life transitions, role histories, and mental health. American Sociological Review, 55, 209_ 223.

Womick, J., Atherton, B., \& King, L.A. (2020). Lives of significance (and purpose and coherence): subclinical narcissism, meaning in life, and subjective well-being, Heliyon, 6(5), e03982. https://doi.org/10.1016/j.heliyon.2020.e03982

Wong, P. T. (1998). Meaning-centered counseling. In Paul T. Wong, P.S. Fry Newjersey (Eds.). The human quest for meaning: A handbook of psychological research and clinical applications (pp. 395-435). Lawrence Erlbaum Associates Publishers.

Yalom, I. D. (2011). Existential psychotherapy. Hachette.

Yavuzer, Y., Albayrak, G., \& Kıllıçarslan, S. (2019). Relationships amongst aggression, self-theory, loneliness, and depression in emerging adults. Psychological Reports, 122(4), 1235-1258. https://doi.org/10.1177/0033294118784866

Yeung, J.W.K., \& Fan, C.P.S. (2013). Being socially isolated is a matter of subjectivity: The mediator of life meaning and moderator of religiosity, Revista De Cercetare St Interventie Sociala, 42, 204-227.

YouGov. (2016). One in four students suffer from mental health problems. https://yougov.co.uk/topics/lifestyle/articles-reports/2016/08/09/quarter-britains-students-areafflicted-mental-hea

You, S., \& Lim, S.A. (2018). Religious orientation and subjective well-being: The mediating role of meaning in life, Journal of Psychology and Theology, 47(1), 1-14. https:// doi.org/10.1177\%2F0091647118795180

Zika, S., \& Chamberlain, K. (1992). On the relation between meaning in life and psychological wellbeing. British Journal of Psychology, 83(1), 133-145. https://doi.org/10.1111/j.2044-8295.1992.tb02429.x 